\title{
PRODUÇÃO CIENTÍFICA BRASILEIRA EM ADMINISTRAÇÃO NA DÉCADA DE 2000
}

Carlos Osmar Bertero carlos.bertero@fgv.br

Professor da FGV-EAESP

Flávio Carvalho de Vasconcelos flavio.vasconcelos@fgv.br

Professor da FGV-EBAPE

Marcelo Pereira Binder marcelo.binder@fgv.br

Professor da FGV-EAESP

Thomaz Wood Jr. thomaz.wood@fgv.br

Professor da FGV-EAESP

\section{GÊNESE DO FÓRUM}

O campo científico da Administração tem crescido com notável vitalidade no Brasil. O número de programas de mestrado e doutorado multiplicou-se nos últimos anos. Os principais eventos do campo, organizados pela Associação Nacional de Pós-graduação e Pesquisa em Administração (ANPAD), estão consolidados, recebem milhares de trabalhos acadêmicos e reúnem um enorme contingente de pesquisado- res. Acompanhando tal movimento, as revistas científicas nacionais vêm crescendo em número e recebendo cada vez mais artigos.

Por outro lado, embora também venha aumentando, a presença de artigos de pesquisadores de instituições brasileiras em revistas internacionais é ainda pequena e não atingiu, com exceções, os periódicos mais prestigiosos do campo. Estudos realizados nas décadas de 1990 e 2000, nas diversas áreas da Administração, concluíram que a produção local era pouco original e reproduzia, com atraso, o que se fazia em centros mais desenvolvidos, especialmente os Estados Unidos (e.g. VERGARA e CARVALHO JR, 1995). Além disso, muitos desses estudos mostraram que a produção havia crescido em quantidade, porém não em qualidade, e que apresentava fragilidades teóricas e metodológicas (veja BERTERO, CALDAS, WOOD JR, 2005a). Suspeita-se que tal realidade não se tenha alterado.

Há oito anos, a RAE-publicações e a Editora Atlas publicaram 
a coletânea Produção Científica em Administração no Brasil: o Estado da Arte (BERTERO, CALDAS, WOOD JR, 2005b). A obra apresentava um balanço do desenvolvimento científico do campo da Administração e de suas áreas, predominantemente focado no período 1990-2000.

Este fórum tem como objetivo atualizar essa avaliação e indicar caminhos para o fortalecimento do campo científico da Administração no Brasil. Propusemos aos autores que realizassem um retrato da evolução de suas respectivas áreas na década de 2000, que preparassem uma avaliação crítica e que trouxessem propostas para a construção do futuro.

Indicamos, ainda, que os textos fossem norteados pelas seguintes questões:

- Como a pesquisa na área evoluiu, em termos quantitativos e qualitativos?

- Quais as forças e fraquezas dos trabalhos em termos teóricos?

- Quais as forças e fraquezas dos trabalhos em termos metodológicos?

- Quão alinhados estão os trabalhos com a realidade local?

- Quão alinhados estão os trabalhos com os desenvolvimentos da comunidade científica internacional?

- A produção científica local reflete a amplitude e a profundidade do campo?

\section{CONTRIBUIÇÕES AO FÓRUM}

O produto desse notável esforço coletivo são os cinco artigos que compõem este fórum, abrangendo as áreas de Comportamento Organizacional, Gestão de Pessoas, Finanças, Gestão de Operações e Marketing. De modo geral, os autores apresentam uma perspectiva crítica da evolução da produção científica no Brasil na década de 2000. Nossa produção cresceu e evoluiu, porém ainda apresenta fragilidades teóricas e metodológicas consideráveis, é pouco relevante e ainda dá os primeiros passos para a inserção internacional.

Filipe Sobral e Juliana Arcoverde Mansur analisaram 185 artigos de Comportamento Organizacional. Concluíram que o campo desenvolveu identidade própria, apresentando grande diversidade de temas, com destaque para cultura organizacional e aprendizagem organizacional. Os autores salientam, entretanto, a fragilidade metodológica e sugerem trilhas para endereçar a questão. Segundo eles:

[...] há necessidade de se ampliar as pesquisas no que diz respeito à escolha epistemológica e utilização de métodos e técnicas adequadas a ela, o que garantiria maior validade científica e, portanto, maior contribuição para o campo de Comportamento Organizacional. Paralelamente, poderia haver uma intensificação de estudos no nível meso e utilização de abordagens multinível, além do aumento de estudos inferenciais, a partir de experimentos e testes controlados. Para a consolidação do campo nos próximos anos, as pesquisas deveriam ainda adotar perspectivas mais amplas em relação a questões teórico-metodológicas. Por exemplo, expor teorias para testes empíricos mais robustos. (SOBRAL e MANSUR, 2013, p. 021-034).

André Ofenhejm Mascarenhas e Allan Claudius Queiroz Barbosa estudaram 32 artigos de Gestão de Pessoas. A análise revelou diversos pontos de atenção: dificuldade para sistematizar tendências na literatura existente, conexão frágil entre teoria e metodologia, detalhamento inadequado das opões metodológicas e discussão insuficiente dos resultados. Segundo os autores:

Construir o impacto da produção brasileira em Administração dependeria de se aprofundar o entendimento sobre sua relevância. [...] Dois caminhos para reflexão emergiriam. O primeiro seria analisar para quem escrevemos. [...] Frente à tendência pela internacionalização, este dilema se resumiria à escolha entre a produção de relevância às agendas anglófonas, concebida implicitamente como agenda internacional, mas relevante principalmente aos países de língua inglesa, e a produção de relevância local, que refletiria o modelo da universidade comprometida com a sociedade civil, que direciona atenção à problemática local sem descuidar de processos globais subjacentes. O segundo caminho seria analisar o que escrevemos. Aqui valeria a proposição de Rousseau, Manning e Denyer (2008), para quem somente a síntese de um corpo de evidências científicas revelaria implicações consistentes à prática, abrangendo acúmulo, análise e interpretação de 
um conjunto de textos. Dado o volume atual da produção científica nacional, seria desejável identificar e sistematizar a contribuição dos textos, sintetizar o conhecimento sendo acumulado, refletir sobre seus limites e desdobramentos, e indicar caminhos para desenvolvimento futuro. (MASCARENHAS e BARBOSA, 2013, p. 035-045).

Ricardo Pereira Câmara Leal, Vinício de Almeida e Souza e Patrícia Maria Bortolon realizaram uma avaliação bibliográfica quantitativa e qualitativa de 461 artigos de Finanças. A análise revela a baixa produtividade dos pesquisadores e a veiculação dos trabalhos em periódicos internacionais de baixo impacto. Os autores argumentam que pouca inovação teórica e metodológica é a razão por detrás da dificuldade para publicar artigos em periódicos de alto impacto. Segundo eles:

Atualmente, parece haver dois mundos: o dos pesquisadores de Finanças vinculados às principais instituições internacionais, que competem para ver seus artigos publicados nos melhores periódicos científicos mundiais da área, e o dos pesquisadores nacionais, que concorrem para publicar seus artigos nos melhores periódicos científicos nacionais, que oferecem quase que o mesmo número de pontos que os primeiros, mas que são desconhecidos no cenário mundial. O sistema de avaliação poderia aproximar estes dois mundos, pois, observando os resultados obtidos neste estudo, a produ- ção da área no país ainda não reflete a amplitude e a profundidade da inovação teórica e metodológica que ocorre nos países mais desenvolvidos. (LEAL, SOUSA, BORTOLON, 2013, p. 046-055).

Ely Laureano Paiva e Luiz Artur Ledur Brito analisaram 39 artigos de Gestão de Operações, com base nos vetores complementares da relevância e do rigor. Os autores concluem que há razoável convergência temática entre a produção brasileira e a produção internacional no campo. Seu principal alerta refere-se à questão do rigor científico e à necessidade de um esforço para inserção internacional. Segundo eles:

[...] um dos principais desafios presentes é atentar para as mudanças de orientação metodológica em curso no cenário internacional. Inicialmente, tanto as pesquisas baseadas em survey como em métodos qualitativos precisam se aproximar do nível de rigor metodológico atual das publicações de primeira linha internacional. Métodos menos utilizados, como experimentos, uso de dados secundários e pesquisa-ação, são também oportunidades. Estes métodos apresentam como vantagem potencial sua proximidade com o mundo empresarial. Ao mesmo tempo, também é importante o uso de múltiplas metodologias integradas e inseridas em projetos de pesquisa abrangentes. Fica $O$ desafio para os nossos programas de Mestrado e Doutorado se inserirem nessa empreitada e formar futuros pesquisado- res capazes de desenvolver pesquisas com estas orientações. (PAIVA e BRITO, 2013, p. 056-066).

José Afonso Mazzon e José Mauro da Costa Hernandez realizaram análise abrangente de 1.272 artigos de Marketing. Os autores confirmaram a importância dos congressos para a veiculação da produção brasileira e identificaram o tema do comportamento do consumidor como aquele que mais atrai pesquisadores. De acordo com os autores, um dos principais pontos de atenção identificados refere-se à relevância:

Verificamos que a expressiva maioria dos trabalhos tem inspiração internacional, retratando aspectos teóricos que estão sendo discutidos nos países mais desenvolvidos. Entretanto, quão alinhados estão esses temas com a nossa realidade? Inúmeros contextos tipicamente brasileiros estão sendo pouco estudados sob o prisma de Marketing, como pobreza e consumo, desenvolvimento de produtos e serviços para a classe baixa e a emergente classe média, tipos particulares de canais (feiras livres, padaria, bares, armazéns, entrega em domicílio) e modalidades de crédito mais frequentes no Brasil que em outros países (prestações, cheques pré-datados, fiado). Apelamos aos autores de Marketing que passem a pelo menos pensar na possibilidade de dedicar mais de seu tempo à investigação de contextos tipicamente brasileiros e que têm sido negli- 
genciados nos últimos anos. (MAZZON e HERNANDEZ, 2013, p. 067-080).

\section{UMA PROVOCAÇÃO À COMUNIDADE CIENTÍFICA LOCAL}

Conforme indicamos na abertura desta apresentação, o campo científico da Administração cresceu com vigor no Brasil na última década. Tal campo se consolidou, no País, sob a égide da Capes, capaz de exercer influência substantiva por meio de seus processos de avaliação. Esse processo tem sido alvo de incômodo e críticas da comunidade científica. Entretanto, ele é influenciado e parcialmente definido por esta mesma comunidade científica. Pode-se, portanto, afirmar, que os resultados obtidos, incluindo sucessos e fracassos, constituem produtos de uma coletividade de pesquisadores.

Imaginemos, por um momento, que o governo federal decidisse privilegiar radicalmente algumas áreas de pesquisa, aquelas vistas como capazes de alavancar o crescimento e ajudar a equacionar as grandes questões nacionais, em detrimento de outras, vistas como improdutivas e frágeis. E que, nesse segundo grupo, incluísse a área da Administração. Imaginemos, ainda, que tal decisão implicasse o fechamento dos grupos de pesquisa e a descontinuidade das revistas e dos eventos científicos. Pergunta-se: seriam as consequências de tal decisão danosas para o País? Seriam as decorrências da medida percebidas pela comunidade científica internacional? Perderiam as empresas e outras organizações locais uma fonte valiosa de reflexão e explicação de fenômenos relevantes?

Se o leitor responder "não" às questões acima, ou ao menos for assaltado por dúvidas, talvez valha a pena dedicarmos alguma energia e algum esforço a pensar o que poderíamos fazer diferente. Então, a questão que se coloca é a seguinte: o que nos ajudaria a consolidar o campo científico da Administração e torná-lo valioso, talvez imprescindível?

\section{COMO CONSTRUIR TEORIAS TROPICAIS}

Parte essencial da missão de qualquer comunidade científica é a construção de teorias, ou seja, a identificação de fenômenos relevantes e a busca de explicações sobre por que ocorrem, como ocorrem e quais são suas consequências (veja VEN, 1989; WHETTEN, 2003). E, como se sabe, "não há nada mais prático do que uma boa teoria" (KURT LEWIN, 1892-1947).

A ecologia organizacional brasileira é complexa, apoiando-se sobre uma economia diversificada e uma textura sociocultural rica e multifacetada. Tal contexto oferece, aos pesquisadores, enormes oportunidades para contribuírem para o desenvolvimento da teoria e para o aperfeiçoamento da prática administrativa.

Considerando o histórico da produção científica no Brasil, incluindo as reflexões abrangidas por este fórum, acreditamos que o desenvolvimento futuro de teorias deverá apoiar-se em três vetores: o uso de teorias desenvolvidas em outros países para explicar fenômenos locais; o desenvolvimento de teorias locais, com base em conhecimento local, voltadas para explicar fenômenos específicos locais; e a busca de rigor na pesquisa científica. Vejamos cada um desses vetores.

O primeiro vetor vem caracterizando a produção local, nos vários campos da Administração. Os pesquisadores brasileiros vêm sistematicamente se apropriando de teorias originadas fora do País, especialmente aquelas produzidas nos países anglo-saxões, e aplicando-as ao contexto local. Tal modus operandi abrange todo o espectro paradigmático, do neopositivismo às teorias críticas, incluindo as abordagens pós-modernas.

Há, naturalmente, valor em realizar tal apropriação e tal aplicação. Pode-se, por meio desse processo, ter acesso às mais modernas teorias para explicar fenômenos locais. Pode-se, também, contribuir para o avanço do conhecimento teórico, comprovando ou negando sua validade em contextos diferentes daqueles em que tais teorias foram geradas.

No entanto, mirando o futuro, para que tal processo seja robusto e gere contribuições significativas, é preciso que ocorra uma escolha esclarecida e estratégica das teorias a serem apropriadas e uma aplicação consistente com a realidade local. Para isso, é preciso romper a apropriação superficial de teorias, praticada nos trópicos, e aprofundar efetivamente o conhecimento sobre os corpos teóricos originados em outros contextos.

O segundo vetor foi menos proeminente na produção local, porém marcou diversas iniciativas de desenvolvimento teórico, tais como aquelas voltadas para a compreensão de fenômenos organizacionais com base em traços 
culturais brasileiros e aquelas focadas em analisar o comportamento do consumidor de baixa renda ou a internacionalização de empresas brasileiras.

Tal vetor constitui uma dupla oportunidade para a comunidade científica local, de gerar contribuições originais para o desenvolvimento teórico, no âmbito da comunidade científica internacional, e de gerar contribuições para a compreensão (e, eventualmente, a ação) sobre questões e problemas locais. Acreditamos que alocar esforços e recursos nesse sentido poderá resultar em um salto qualitativo para a produção científica local.

O terceiro vetor perpassa os vetores anteriores, constituindo condição necessária para a realização de contribuições teóricas relevantes. O rigor refere-se à competência para utilizar métodos de pesquisa, sejam de abordagens qualitativas ou quantitativas, e também à competência de construção teórica. Esse último item envolve o domínio do estado da arte no campo e a capacidade de desenvolver teorias para explicar fenômenos relevantes.

Evoluir, em termos de rigor, constitui um grande desafio para os pesquisadores brasileiros, mesmo considerando o desenvolvimento ocorrido nos últimos anos. Conforme observado anteriormente, nossa comunidade tem praticado formas acríticas de mimetismo, reproduzindo com atraso teorias originadas em outros países (veja BERTERO, CALDAS, WOOD JR, 2005b).

\section{OITO PROPOSTAS PARA 0 PRESENTE MILÊNIO}

Têm surgido, no âmbito da comunidade científica local, diversos textos críticos sobre o chamado "produtivismo acadêmico" (e.g, ALCADIPANI, 2011; FARIA, 2011; FREITAS, 2011; GODOI e XAVIER, 2012; MACHADO E BIANCHETTI, 2011; MATTOS, 2012). Tais textos, de modo geral, ecoam críticas da comunidade local ao caráter quantitativo fomentado pelo sistema de mensuração e avaliação de resultado da Capes. Esse sistema estaria levando nossos pesquisadores a privilegiarem a quantidade em favor da qualidade e a favorecerem a publicação em favor do impacto, adotando, assim, uma lógica de produção em série, própria das linhas de produção fordistas.

As críticas têm méritos, pois chamam a atenção para desvios substantivos da atividade científica. De fato, o produtivismo pode também ser visto como mimetismo de uma atitude que se desenvolveu no mundo acadêmico dos países desenvolvidos, lá também encontrando os seus críticos. No entanto, a mentalidade produtivista, hoje presente na academia brasileira, é mais do que o reflexo atitudinal e comportamental de cientistas, provocado por um modelo de medição da produção. Trata-se, na verdade, de um sistema construído ao longo do tempo e sustentado por seus diversos agentes: os programas de mestrado e doutorado, os eventos científicos, as revistas científicas, os agentes reguladores e o próprio corpo de pesquisadores. Tal sistema sustenta um modo próprio de geração e disseminação de conhecimento. Além disso, ajuda a promover certos valores e práticas, fomentando uma cultura peculiar de pesquisa.

Considerando tais críticas e as reflexões trazidas pelos autores do presente fórum, acreditamos que a comunidade científica de Adminis- tração no Brasil poderia beneficiar-se de um diálogo norteado por temas específicos de mudança. Para isso, listamos a seguir oito propostas para reflexão.

\section{Focar o Brasil}

As revistas científicas brasileiras deveriam ter um papel mais ativo e estabelecer linhas editoriais que privilegiem o desenvolvimento de conhecimento e teorias sobre temas, objetos e fenômenos brasileiros. Deveriam, também, aprofundar a segmentação por campo e por orientação ontológica. Hoje, nossas principais revistas, salvo exceções, aceitam artigos oriundos de todos os campos da Administração e de qualquer orientação ontológica. Tal condição cria enorme desafio para os editores e corpos de avaliadores, levando a processos longos e inadequados de revisão. Algumas delas começam a aceitar artigos internacionais, eventualmente sobre temas distantes da realidade brasileira. Pensamos que revistas científicas locais, focadas na realidade local e segmentadas por campo, trariam uma contribuição mais efetiva para o desenvolvimento do campo da Administração no Brasil. Além disso, a comunidade acadêmica internacional provavelmente teria interesse maior em ler e aprender sobre o Brasil por meio de pesquisadores brasileiros do que vê-los mimetizando e reproduzindo teorias desenvolvidas nos países centrais.

\section{Aproximar teoria e prática}

As instituições de ensino deveriam buscar maior proximidade entre desenvolvimento teórico e prática organizacional. A Administração, como se sabe, é uma 
ciência aplicada. Isso não signifi$\mathrm{ca}$, obviamente, que a agenda de seus pesquisadores deva ser balizada pelas preocupações de momento de empresários e executivos. Tampouco significa que seus pesquisadores possam se isolar do mundo da prática. O desafio é gerenciar a relação entre esses dois mundos. Hoje, muitos pesquisadores das instituições brasileiras atuam distantes das organizações. É preciso estabelecer fóruns de diálogo e cooperação, que permitam a aproximação entre pesquisadores e gestores, de modo a construir agendas de pesquisa que possam tanto fazer avançar a teoria sobre fenômenos locais quanto contribuir para a reflexão sobre as práticas administrativas e seu aperfeiçoamento. A Administração é considerada igualmente uma área social aplicada. Ora, o País está longe de ser bem administrado. Isso é válido tanto para a área pública como para a área empresarial. Basta observar a má administração de recursos, a má qualidade dos serviços e a má gestão de projetos, que acarretam imenso prejuízo para toda a sociedade. Há diversas razões para a existência desse tipo de problema, mas certamente a baixa qualidade da gestão arca com parte da responsabilidade. Contribuir para uma melhoria da prática administrativa é missão importante da área.

\section{Criar planos de pesquisa}

Os programas de mestrado e doutorado deveriam desenvolver planos de pesquisa. Hoje, diversos programas estabelecem metas atreladas ao sistema de avaliação Capes, buscando evoluir em termos de classificação geral. Tal sistema, como se sabe, utiliza uma série de critérios, entre os quais se encontra a pontuação atingida pelos professores pesquisadores, por meio de publicações em periódicos. Para gerar conhecimento e melhores teorias, os programas deveriam ir além das metas numéricas, estabelecendo diretrizes de pesquisa voltadas para a construção de conhecimento em torno de determinados temas, objetos e fenômenos. Tais escolhas deveriam ser coerentes com a história das instituições de ensino, as competências já estabelecidas e sua inserção local, regional e internacional. Naturalmente, tais diretrizes deveriam também preservar a liberdade acadêmica, pedra fundamental do desenvolvimento científico, garantindo espaço para a diversidade de perspectivas e abordagens que caracterizam o campo.

\section{Fomentar o rigor}

Os gatekeepers, especialmente os editores de revistas científicas e coordenadores de áreas de eventos científicos, deveriam atuar com maior rigor. Hoje, os eventos e revistas são frequentemente vistos como "escoadouros" para a produção científica. Parece haver uma premissa tácita de que tudo que é produzido com um mínimo de qualidade deveria ser veiculado. Tal condição infla as pontuações dos programas, facilitando o cumprimento de suas metas de produção científica. Entretanto, torna nossos outlets vitrines de trabalhos de baixo rigor e baixa qualidade. Pensamos que uma atuação mais criteriosa e restritiva dos gatekeepers contribuiria para o aumento da qualidade da produção local, barrando os trabalhos de menor relevância e estimulando aqueles de maior potencial, para que se trans- formem em contribuições científicas realmente importantes.

\section{Focar o impacto da produção}

O sistema nacional de avaliação deveria deslocar seu foco da produção para o impacto. Conforme indicamos anteriormente, tal sistema utiliza uma série de critérios, entre os quais a pontuação atingida pelos professores pesquisadores, por meio de publicações em periódicos, locais e estrangeiros. Esse sistema, como se sabe, tem provocado distorções, pois vem estimulando pesquisadores a "multiplicar" publicações para garantir maior pontuação. Com isso, a quantidade frequentemente avança em detrimento da qualidade. Alguns programas de pós-graduação chegam a induzir expedientes condenáveis para inflar seus números. Indicadores de impacto, por sua vez, deslocam o foco da produção para a utilização do conhecimento. Exigem, naturalmente, uma apuração mais sofisticada.

\section{Privilegiar periódicos internacionais de alto nível}

Os sistemas de incentivo deveriam privilegiar a veiculação em periódicos de alto nível. Algumas instituições de ensino implementaram sistemas de incentivo, frequentemente visando fomentar a internacionalização da pesquisa, estimulando seus pesquisadores a participarem de redes científicas internacionais, desenvolverem projetos em parceria com colegas de instituições no exterior e publicarem artigos em periódicos estrangeiros. Consideramos desejável haver um reconhecimento especial para artigos veiculados nos principais periódicos interna- 
cionais, aqueles com maior fator de impacto, de ampla visibilidade na comunidade internacional. Hoje, a pressão por publicações internacionais, contraposta à limitada tradição brasileira em pesquisa, tem levado muitos pesquisadores locais a buscar revistas internacionais de baixo fator de impacto. Tal condição limita nossa audiência e não contribui para o aumento do rigor e da qualidade da pesquisa. A experiência de publicar nos principais periódicos, por outro lado, exigiria o desenvolvimento de competências específicas, em termos de desenvolvimento teórico e métodos, que poderia irradiar-se dos autores para seus programas. Além disso, a veiculação de trabalhos nesses periódicos poderia dar visibilidade internacional para a produção local e contribuir para o desenvolvimento de teorias mais robustas, validadas (ou não) em um país emergente.

\section{Reformar os programas de pós-graduação}

As instituições de ensino deveriam tomar medidas mais firmes para garantir a qualidade da formação de futuros pesquisadores. Hoje, há um incentivo ao crescimento dos programas, visando aumentar o número de mestres e doutores. Tal objetivo é coerente com o objetivo maior de sustentar o crescimento da atividade de pesquisa no País. $\mathrm{Na}$ prática, entretanto, o que se observa é um descolamento entre aspiração e realidade, pois muitos egressos não têm perfil científico e de pesquisador, e não seguirão carreira acadêmica. Programas de doutorado mais restritos e exigentes, com forte incentivo para a realização de períodos de estudo e pesquisa no exterior, provavel- mente apresentariam uma relação mais favorável entre os recursos investidos e os resultados obtidos. Em paralelo, os programas de mestrado poderiam continuar a ser ampliados, com maior foco na formação de docentes e considerando que uma parcela restrita, porém representativa, de egressos viria a cursar o doutorado.

\section{Reconhecer pesquisadores e pesquisas exemplares}

As instituições deveriam celebrar pesquisadores e pesquisas exemplares. O sistema de pesquisa em Administração implementado no Brasil está formando gerações de pesquisadores dentro de uma lógica burocrática de produção intelectual. É certo que a ciência moderna precisa lidar com desafios relacionados ao planejamento, à alocação e à gestão de recursos. Entretanto, é preciso estar alerta aos excessos. Nossos doutorandos e jovens doutores preocupam-se cada vez mais com suas publicações e pontuações e cada vez menos com a construção sólida de conhecimento e com o desenvolvimento de contribuições científicas consistentes. Pensamos que nossas instituições deveriam celebrar pesquisadores que, por seu idealismo e conduta coerente, tivessem trazido contribuições notáveis ao desenvolvimento do campo. Deveriam, também, premiar trabalhos excepcionais de pesquisa, que representassem marcos para a construção do conhecimento. Acreditamos que é preciso recuperar o "ethos do cientista", que perdeu força nos últimos anos na academia brasileira, em detrimento da ascensão dos burocratas da pesquisa e dos articuladores políticos. De fato, essas observações podem ser estendidas à comunidade acadêmica internacional. Significativamente, boa parte dos textos que hoje lemos como clássicos e usamos no treinamento de mestres e doutores foi produzida por acadêmicos distantes da lógica do produtivismo. Produziram menor quantidade, porém com melhor qualidade e, especialmente, com maior relevância.

\section{CONCLUSÃO}

Em um editorial sobre a evolução de estudos organizacionais na China, Tsui argumenta:

\begin{abstract}
Nas duas últimas décadas, a pesquisa sobre gestão chinesa utilizou questões, teorias, construtos e métodos desenvolvidos no contexto ocidental. Estão faltando estudos exploratórios que tratem de questões relevantes para as empresas chinesas e o desenvolvimento de teorias que ofereçam explicações significativas sobre os fenômenos chineses. (TSUI, 2009, p. 1).
\end{abstract}

As similaridades entre a situação chinesa e a situação brasileira podem ser mais do que meras coincidências. Os dois países emergentes têm aspirações internacionais, porém correm o risco de, ao tentar aderir ao sistema internacional de geração de conhecimento, entrar pela porta dos fundos e perder o foco na própria realidade, rica e em rápida mutação.

Em um outro editorial, sobre desenvolvimento teórico, Suddaby, Hardy e Huy (2011) realizam uma reflexão crítica incomum sobre $\mathrm{O}$ 
desenvolvimento de novas teorias sobre organizações na academia internacional. Os organizadores indicam que, significativamente, não receberam para a organização de seu fórum artigos com novas teorias, porém receberam vários textos com autocríticas e sugestões para desenvolver novas teorias. Observam, ainda, que as teorias atualmente usadas por autores e pesquisadores referem-se a desenvolvimentos teóricos ocorridos até a década de 1970. Suddaby, Hardy e Huy apontam o reducionismo e o conservadorismo da pesquisa no campo, e o distanciamento entre teoria e prática. Tal constatação pode ser complementada pela crítica realizada por Gabriel (2010), que argumenta que as publicações acadêmicas se transformaram em lugares burocráticos e políticos e que a ciência normal foi substituída por uma proliferação de teorias e vozes que se tornaram incompreensíveis e irrelevantes para a prática administrativa.

Tais considerações, sobre a academia chinesa e sobre a academia internacional, reforçam a noção de que a academia brasileira do campo da Administração vive um bom momento para realizar escolhas estratégicas e implementar mudanças. Os méritos e deméritos de nossa academia são há muito tempo conhecidos e discutidos. Sempre que uma reflexão crítica é estimulada, como no caso deste fórum, geram-se conclusões similares. O País e suas organizações bem mereceriam uma academia mais "extrovertida", capaz de teorizar sobre os fenômenos locais e de interagir de igual para igual com seus pares internacionais. Cabe, portanto, neste ponto deste texto de apresentação, uma pergunta final: será possível reformar nossa academia, para que responda de maneira mais efetiva a tais aspirações?

Os mais otimistas provavelmente argumentarão que o norte está definido, que as trilhas gerais estão traçadas e que, mais cedo ou mais tarde, chegaremos lá. Quiçá justifiquem sua posição mostrando a sensível evolução ocorrida nos últimos anos, em termos de produção científica, veiculada no Brasil e no exterior. Acreditamos, no entanto, que o sistema, fortemente inercial, demanda ajustes substantivos, como os sugeridos acima. Sem tais ajustes, nossa comunidade científica permanecerá como uma torre de marfim, erigida em uma ilha tropical, tenuemente ligada ao contexto local e ao mundo exterior. Se os agentes com poder de influência não se mobilizarem para a mudança, então um futuro fórum sobre a produção científica em Administração no Brasil, realizado daqui a 10 anos, chegará a conclusões similares às deste fórum e a outras reflexões realizadas anteriormente (e.g, BERTERO, CALDAS, WOOD JR, 2005b). Desejamos que isso não ocorra.

\section{REFERÊNCIAS}

ALCADIPANI, R. Resistir ao produtivismo: uma ode à perturbação acadêmica. Cadernos EBAPE.BR, v. 9, n. 4 , p. 174-178, 2011.

BERTERO, C. O; CALDAS, M. P; WOOD Jr, T. Introdução: produção científica em administração no Brasil. In: BERTERO, C. O; CALDAS, M. P; WOOD Jr, T. Produção científica em administração no Brasil: o estado da arte. São Paulo: Atlas, 2005a.
Bertero, C. O; CAldas, M. P; WOOD Jr, T. Produção científica em administração no Brasil: o estado da arte. São Paulo: Atlas, 2005b.

FARIA, A. Repensando produtivismo em gestão no (e a partir do) Brasil. Cadernos EBAPE.BR, v. 9, n. 4, p. 1164-1173, 2011.

FREITAS, M. E. O pesquisador hoje: entre o artesanato intelectual e a produção em série. Cadernos EBAPE.BR, v. 9, n. 4, p. 1158-1163, 2011.

GABRIEL, Y. Organization studies: a space for ideas, identities and agonies. Organization Studies, v. 31, n. 6, p. 757-775, 2010.

GODOI, C. K; XAVIER, W. G. O produtivismo e suas anomalias. Cadernos EBAPE. BR, v. 10, n. 2, p. 456465, 2012.

LEAL, R. P. C; SOUSA, V. A. e; BORTOLON, P. M. A produção científica brasileira em finanças no período 2000-2010. RAE-Revista de Administração de Empresas, v. 53, n. 1, p. 046-055, 2013.

MACHADO, A. M. N; BIANCHETTI, L. (Des)fetichização do produtivismo acadêmico: desafios para o trabalhador-pesquisador. RAE-Revista de Administração de Empresas, v. 51, n. 3, p. 244-254, 2011.

MASCARENHAS, A. O. M; BARBOSA, A. C. Q. A produção científica brasileira em gestão de pessoas no período 2000-2010. RAE-Revista de Administração de Empresas, v. 53, n. 1, p. 035-045, 2013.

MATTOS, P. L. C. L. Pés de barro do texto "produtivista" na academia. RAE-Revista de Administração de Empresas, v. 52, n. 5, p. 566-573, 2012. 
MAZZON, J. A; HERNANDEZ, J. M. C. A produção científica brasileira em marketing no período 2000-2009. RAE-Revista de Administração de Empresas, v. 53, n. 1, p. 067-080, 2013.

PAIVA, E. L; BRITO, L. A. L. A produção científica brasileira em gestão de operações no período 2000-2010. RAE-Revista de Administração de Empresas, v. 53, n. 1, p. 056-066, 2013.

ROUSSEAU, D; MANNING, J; DENYER, D. Evidence in management and organizational science: assembling the field's full weight of scientific knowledge through syntheses. AIM Working Paper Series, 067, 2008. Disponível em: http://www.evidencebased-management.com/wp-content/uploads/2010/01/ROUSSEg PapaersAU-Evidence_2_15_08-11.pdf. Acesso em 23.03.2011.

SOBRAL, F; MANSUR, J. A produção científica brasileira em comportamento organizacional no período 20012010. RAE-Revista de Administração de Empresas, v. 53, n. 1, p. 021-034, 2013.

SUDDABY, R; HARDY, C; HUY, Q. N. Introduction to special topic forum: where are the new theories of Organization? Academy of Management Review, v. 36, n. 2, p. 236-246, 2011.

TSUI, A. S. Editor's introduction - autonomy of inquiry: shaping the future of emerging scientific communities. Management and Organization Review, v. 5, n. 1, p. 1-14, 2009.

VEN, A. V. de. Nothing is quite so practical as a good theory. Academy of Management Review, v. 14, n. 4, p. 486-489, 1989.

VERGARA, S. C; CARVALHO Jr, D. S. Nacionalidade dos autores referencia- dos na literatura brasileira sobre organizações. In: ENCONTRO NACIONAL DA ASSOCIAÇÃO NACIONAL DOS PROGRAMAS DE PÓS-GRADUAÇÃO EM ADMINISTRAÇÃO, 19, 1995, João Pessoa. Anais. João Pessoa: ANPAD, 1995.

WHETTEN, D. A. O que constitui uma contribuição teórica? RAE-Revista de Administração de Empresas, v. 43, n. 3, p. 69-73, 2003. 